At present the projected legislation will restrict the prescribing of only heroin and cocaine. As cocaine is not a drug that can produce physical dependence there is no reason to prescribe this drug in any circumstances. There may have to be an extension of the drugs restricted at a later date, as already many addicts who have taken heroin and cocaine in the past take intravenous methadone combined with methedrine at present. Prescribing methadone for addicts is not desirable. If there is to be medical control it is better dispensed and given orally under supervision. Whether patients of this type can best be treated voluntarily or compulsorily will have to be considered. The most convincing follow-up studies up to the present have shown that a period of compulsory treatment followed by a probationary period on licence produced better results than purely voluntary or purely custodial methods of treatment. ${ }^{4}$

\section{REFERENCES}

1 Ministry of Health, H.M.(67) $16: 13$ (a).

- Dole, V. P. et al., Arch. intern. Med., 1966, 118, 304.

- Wislicki, L., Brit. F. Addict, 1963, 59, 37.

- Vaillant, G. E., Amer. F. Psychiat., 1966, 122, 727.

\title{
Importance of Research
}

\author{
From Dr. P. H. Connell, Physician, Bethlem Royal and Maudsley Hospital, London
}

For the purposes of this short contribution I shall consider some of the recommendations of the Brain Committee under four main headings-namely, outpatient services, inpatient services, maintenance, and general considerations.

Outpatient Services.-It is generally agreed that outpatient services should be sited within the addiction prevalence areas, and that close contacts with the community served will be essential. In London this will mean that the teaching hospitals which serve the addict population may be involved. There are thus fears that large numbers of addicts will descend upon the general outpatient department, and not only overload it but also cause undesirable effects, such as spreading the addiction to other patients and disturbing the department by bad behaviour. Similar arguments are used when considering a psychiatric outpatient department. Moreover, it must be recognized that many hospitals have outpatient departments and psychiatric departments which are already severely overextended.

In my view, therefore, there can be no hard-and-fast rule as to the siting of addiction outpatient services, which will have to be provided according to local conditions. In general terms, however, there is no direct evidence to suggest that there will be an influx of large numbers of addicts, provided that maintenance attendances are cut down to, say, once in two weeks, and provided that a large enough number of hospitals cater for addicts, so that the load is well spread. Nor is there any direct evidence that the presence of addicts in psychiatric outpatient departments necessarily causes distress to other psychiatric patients. In general, difficulty would not seem to be likely unless the addicts formed a group and settled themselves, for instance, in the canteen. The operative factor here would seem to be the proportion of addicts in relation to the other categories of patients seen. Thus some hospitals would need separate outpatient facilities for addicts, but others could cope without these.

Rehabilitation will be a central feature of the therapeutic spectrum, and without this the efforts of both inpatient and outpatient treatment may come to naught. It is likely that only the exceptional patient will be suitable for the general psychiatric rehabilitation service, and hence I think that there should be urgent provision of a few hostels - on an experimental and exploratory basis-in the London area linked by joint staff to the main centres of treatment. The role of the hostel would be to provide support and supervision for the addict, and gradually to introduce him to and integrate him into the community and to prevent him going back to the addict subculture, which has previously provided psychological sustenance and support of a deleterious nature. For example, "industrial therapy" at a hostel or from a hostel could be provided, while other methods of rehabilitation (such as boarding out with families) should be explored.

Inpatient Services.-Urgent admission of the addict may be needed either because of physical illness or because he has reached the stage of wishing for treatment, and it is essential to admit him while he is in this frame of mind. In general, apart from physical illnesses which cannot be nursed in a psychiatric ward, I think that the general medical ward is not a suitable place for the addict, and it is rarely possible to provide adequate supervision. Moreover, admission to general psychiatric beds on a "dilution" principle has, in my view, proved to be unsatisfactory, firstly because the problems of the addict are different from general psychiatric problems, and secondly because the addict draws to him antagonisms from the other psychiatric patients as well as from nurses and doctors because of the difficulties he produces. Thus, provided it is small enough (say, 10-12 beds), a separate unit for addicts would have a number of advantages, including the development of a team approach to the addict; providing the opportunity to study methods of treatment and control; and cutting down the danger of spread of addiction to other psychiatric patients. This does not necessarily mean closed units, but does mean very close relationships between the staff of the addiction unit and the staff of the rest of the hospital.

Withdrawal from the narcotic is in my view best done in the addiction unit rather than elsewhere, since it is an advantage therapeutically for the same nurses and doctors who are to treat the underlying problems to have also helped the patient through the withdrawal crisis.

I believe that the case for compulsory admission or compulsory detention in a crisis has not been made. There are many reasons against compulsory admissions of addicts, and I feel that the whole question should be kept under review so that adequate data may be obtained.

Maintenance.-The prescribing of heroin to an addict is anathema to many doctors. Nevertheless, in my view the case has been well made for attempting such an approach, both to contain the spread of addiction and to try to prevent the development of large-scale criminal activities in this field. Acceptance of the maintenance method does not necessarily mean acceptance for all time, and it will be important that yearly reviews be made to assess the impact of this approach and to think again if the method has failed to influence events.

There are certain provisos to this approach:

1. It is essential that a uniform scheme of maintenance should be used in all maintenance centres, and that the scheme is rigid enough to debar prescription of heroin to an addict because he has lost his drug or sold it or given it away. If an addict comes 
with such a story and his wishes are met gross overprescribing will continue. Such a person can be offered admission for treatment and supervision.

2. It is essential that careful records should be kept and that close liaison with the Home Office in relation to records, notification, etc., should take place.

3. Adequate procedures must be evolved to cope with the addict who has moved out of his area.

General Considerations.-The question "Who is fit to treat the addict ?" is relevant here. There are few persons-either doctors, nurses, or social workers-who have knowledge or experience in this rapidly developing field. It will be important, therefore, that training is provided at the outpatient and inpatient centres. Clearly, to set up many outpatient services staffed by people who have little basic knowledge or little basic interest in the problems of addiction may well be disastrous. This conflicts with the need to spread the outpatient case load to many hospitals, and one compromise would be to select hospitals suitably situated geographically and to concentrate the available resources on these, also training staff there to set up other clinics.

The question of the place of voluntary bodies and interested persons in such fields as education, the Church, and so on is a difficult one. That there may be a place cannot be denied, and possibly such people have a major contribution to make. Nevertheless, ability to be reasonably objective is particularly important in the field of drug addiction, and the drug addict is often a past master at manipulating those who are emotionally involved.

A factor which is often underemphasized is the need for supporting laboratory services. This is particularly important in relation to the supervision of the patient by regular estimations of blood or urine or both to demonstrate the presence or absence of drugs. Without such backing the clinician may be misled or confused as to the real situation.

The Brain Committee's second report dealt only with drugs covered by the Dangerous Drugs Act, though it stepped out- side its terms of reference to mention concern about other drugs, particularly amphetamine and amphetamine-barbiturate mixtures. It is a fact that many adolescents who have taken amphetamines for two or three years are now moving on to heroin. To limit services to narcotic addicts and neglect the non-narcotic-takers, who are larger in numbers and who may well later go on to heroin, would be a grave mistake, and I would therefore urge that provision is made for nonnarcotic users as a direct treatment endeavour and as a contribution to preventing the spread of heroin-taking. It would be academically and practically sound if this field could be regarded as the field of drug dependency, and from the research point of view such an approach would have considerable advantages.

The Brain Committee accentuated the need for research, and I agree fully with this emphasis. Research needs staff at all levels, but perhaps the most urgently needed research is the biochemical research into the development of tests which would quantify not only levels of drug in biological fluids but also would indicate a dose range the patient may have taken. Without such objective measures the hospital doctor will be in the same position as the general practitioner when facing a heroin addict who claims to be taking 8 grains of heroin. Urgent support to laboratories in university, hospital, or services such as the Poisons Reference Services will be necessary.

Finally, in the effort to prevent excess heroin reaching free circulation through addicts, it must not be forgotten that many addicts obtain money from the sale of the heroin additional to their requirements and buy their food, pay rent, etc., with this money. If excess heroin distribution is cut down to a minimum it will be necessary to ensure that the Ministry of Social Security and other agencies are sympathetic to the needs of the addict, recognizing that many are quite unable to obtain their own living in competition in the open market. Failure to show sympathy in this way may well lead to unfortunate consequences.

\section{P. H. Connell.}

\title{
Treatment in the Community
}

\author{
From Dr. P. A. L. Chapple, General Practitioner, London S.W.3
}

Institutional treatment of addiction has been an almost complete failure' (except for a few special units still on trial) throughout the world, because it has created a situation where the patient finds himself in conflict with his doctors-often being forced to relinquish drugs against his will-but also because it fails to face the real problem, which is that of teaching the addicted patient to live in society without using drugs, or, if he must use some drugs, to use those which are as lightly addicting as possible, and to use the oral route in preference to the intravenous route.

Since setting up the Chelsea Addiction and Research Centre, we have dealt with 120 patients, all of whom were initially taking heroin. Of those at present under treatment (61) after three months 38 are no longer using heroin, and cocaine is rarely prescribed by us. They are all treated within the framework of the National Health Service, and there are no private patients in addiction. About 20 patients are seen every day; between five and ten attend our occupational centre (which is run in conjunction with the Salvation Army); and 20 patients who are no longer taking drugs are being followed up. All our patients reside in the community, and, following a modified form of the treatment of Dole and Nyswander, ${ }^{2}$ it has been shown that it may well be possible to treat addicts in the community without prolonged stay in hospital. This is essential if the present number of addicts are to be treated satisfactorily. For this it is necessary to have a high ratio of staff to patients, frequent biochemical checks both to assess progress objectively ${ }^{3}$ and to assist in diagnosis, ${ }^{4}$ a continuity of experienced practitioners, and a human and friendly therapeutic atmosphere.

Because of the nature of general practice, which involves daylong attendance, we are much more accessible to our patients than would be a bi-weekly clinic. Private practice in addiction is open to abuse, both because the addict has to raise money for his drugs and because the doctor may be persuaded to give longer than daily prescriptions for financial reasons.

It is the long-sustained, fluctuating, prolonged battle with his illness and himself that calls forth the support, sympathy, and treatment by the doctor of his patient. Addicts are often initially paranoid, have difficulty in telling the truth about themselves, and equate all people with authority figures, and therefore view them with hostility. To break down these ingrained habits takes time; we are attempting to do this in the atmosphere of a therapeutic community.

The setting up of treatment centres requires a team of experienced workers and takes considerable time to achieve. In calling for the setting up of such centres the Second Interdepartmental Committee Report was flying in the face of estab- 